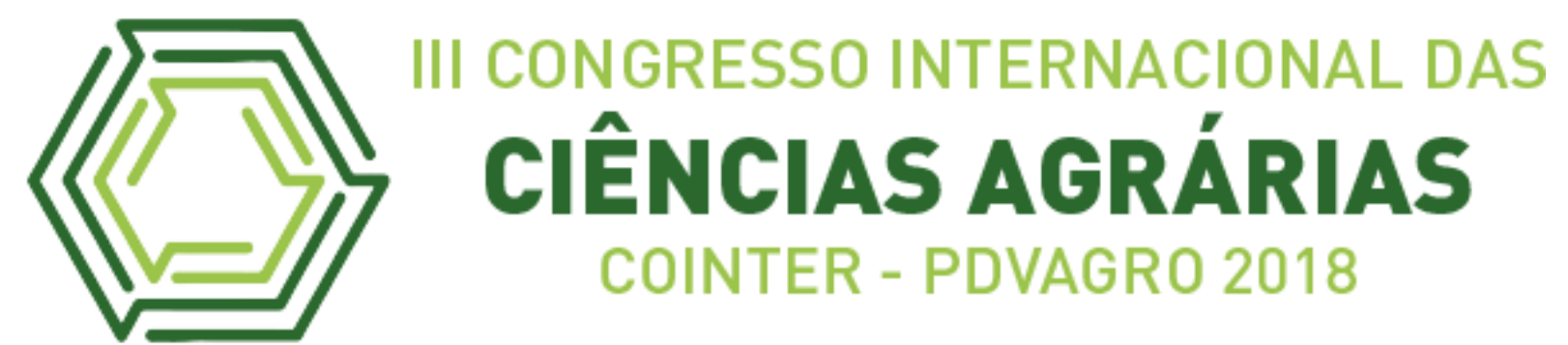

\title{
COMPARAÇÃO ENTRE CAFÉ SOMBREADO PRODUZIDO NO MACIÇO DE BATURITÉ E CAFÉ AO SOL COMERCIAL
}

\section{DIFFERENCE BETWEEN SHADED COFFEE PRODUCED IN MACIÇO DE BATURITÉ AND COMMERCIAL COFFEE}

\author{
Apresentação: Pôster \\ Janaina de Souza Oliveira ${ }^{1}$; Francisco Izaías da Silva Aires ${ }^{2}$; Pedro Vinicius Costa \\ Medeiros $^{3}$; Francisco Aglauberto de Lima Gouveia ${ }^{4}$; Lívia Paulia Dias Ribeiro.
}

\section{DOI: $\underline{\text { https://doi.org/10.31692/2526-7701.IIICOINTERPDVAGRO.2018.00380 }}$}

\section{Introdução}

O interesse em produtos orgânicos, de excelente qualidade e produzidos de manejo diferenciado, vem contribuindo para o crescimento exponencial do mercado alternativo. $\mathrm{O}$ café orgânico do Maciço de Baturité é também chamado de café sombreado pelo sistema agroflorestal que é feita a sua produção. O sistema agroflorestal tem ganhado muita importância econômica mundialmente pela procura dos consumidores aos produtos agrícolas produzidos com manejo alternativo e que utilize recursos naturais de forma sustentável. No Maciço de Baturité, o café é produzido debaixo da sombra de ingazeiras (Ingá ingoides), bananeiras (Musa ssp.) e/ou camunzé (Pithecellobium polycephalum) garantindo a recuperação dos cafezais, mediante a recuperação do solo e seus grãos têm características diferentes do café ao sol, em virtude da lenta maturação (SILVA, 2015). O café produzido no Maciço de Baturité tem ganhado mercado consumidor em Fortaleza, como também no setor turístico na Serra de Guaramiranga. O valor comercial do café cultivado a sombra pode chegar até 5 vezes maior que o café comercializado nos supermercados. O presente trabalho propõe a comparação entre os teores de umidade e cinzas de 4 espécies diferentes de café

\footnotetext{
1 Licenciatura em Química, Universidade da Integração Internacional da Lusofonia Afro-Brasileira, janadesouza1996@yahoo.com.

2 Licenciatura em Química, Universidade da Integração Internacional da Lusofonia Afro-Brasileira, izaias.aires20@gmail.com.

3 Licenciatura em Química, Universidade da Integração Internacional da Lusofonia Afro-Brasileira, pedrovmedeiro@gmail.com.

${ }^{4}$ Bacharelado em Agronomia, Universidade da Integração Internacional da Lusofonia Afro-Brasileira, aglaubertogouveia@gmail.com.

${ }^{5}$ Titulação, Instituição, e-mail
} 
arábica produzidas no Maciço de Baturité produzidos em diferentes cidades da região, e de amostras de café comumente comercializado nos supermercados.

\section{Fundamentação Teórica}

O cultivo do café no Brasil é feito tanto com sombreamento quanto a pleno sol, no entanto, percebeu-se que em algumas regiões o cultivo a pleno sol causava a supressão da vegetação e posteriormente, a degradação do solo, diminuindo a produção cafeeira. Nesse contexto, surge o café sombreado que além de permitir a sombra para o plantio, conserva o solo, reduz as pragas invasoras e produz húmus para a plantação, garantindo, dessa forma, a recuperação da atividade cafeeira (FERNANDES et al., 2011). Essa técnica também proporciona uma lenta maturação dos grãos, o que torna essa produção especial, haja vista que o mercado nacional e mundial tem valorizado esses produtos ofertando um melhor financiamento aos produtores que se dedicam a esse tipo de produção (MANCUSO et al., 2013).

No Brasil, a maioria dos produtores prefere o cultivo a pleno sol por acreditarem que o sombreamento diminui a produtividade, retardado a comercialização pelo retardamento da maturação dos grãos e porque o cultivo sombreado representa maior necessidade de mão-deobra humana causada pela dificuldade na passagem de máquinas e manejo. Estima-se que mais de $90 \%$ das lavouras existentes no Brasil são de pleno sol, com cultivo à sombra predominantemente na região Norte, sudeste. No nordeste o Maciço de Baturité/CE é uma das regiões mais importante para o cultivo do café sombreado.

O café sombreado é uma das culturas que empregam o sistema agroflorestal desenvolvido no Brasil. Quando o cafezal no sistema agroflorestal é comparado com cultura solteira diversos fatores de qualidade do solo apresentaram diferença, como maior teor de umidade, maior fertilidade do solo nos parâmetros de macronutrientes, no entanto maior teor de fósforo e matéria orgânica (CAMPANHA et al., 2007). Estas características do solo podem definir a qualidade do produto colhido, e assim torna distinta a qualidade dos grãos do café quando cultivado em diferentes condições.

A secagem do café é uma etapa de grande importância para valorização do produto. $\mathrm{O}$ café é um dos produtos que o valor comercial cresce significativamente com a melhoria da sua qualidade e o processo de secagem contribui fortemente no preço do café. 
O café precisa está seco independente do recurso utilizado para a secagem, porque qualquer alteração no teor de umidade pode causar prejuízo ao agricultor, como aumento de microrganismos. Independentemente a classificação do café, os grãos não poderá exceder os limites máximos de tolerância de 12,5\% do teor de umidade (MAPA, 2008).

\section{Metodologia}

Os teores de umidade e cinzas de 4 espécies de cafés produzidos em diferentes cidades do Maciço de Baturité e da mistura de café cultivado ao sol comumente comercializados em supermercados foram determinados, em triplicatas, segundo metodologia descrita em Instituto Adolfo Lutz (2008). As amostras foram adquiridas torradas e moídas, diretamente nas propriedades de cultivo, nos meses de maio e junho de 2018.

A amostra do café cultivado ao sol comumente comercializado foi composta pela mistura de 10 marcas diferentes com igual proporção, de 1 pacote para cada marca, adquiridos no mês de maio de 2018.

\section{Resultados e Discussões}

Os resultados obtidos dos teores de umidade e cinzas estão apresentados na Tabela 1, com valores médio e desvio padrão de 3 triplicatas.

Tabela 1. Resultados dos teores de umidade e cinzas das amostras de café sombreados produzidos na região do Maciço de Baturité e café comercial $(\mathrm{n}=3)$

\begin{tabular}{lll}
\hline & Umidade $\%\left(\mathrm{~m} \mathrm{~m}^{-1}\right)$ & Cinzas \% $\left(\mathrm{m} \mathrm{m}^{-1}\right)$ \\
\hline Typica & $2,3 \pm 0,2$ & $4,2 \pm 0,0$ \\
Catuaí vermelho & $2,5 \pm 0,2$ & $4,3 \pm 0,4$ \\
Catuaí amarelo & $2,4 \pm 0,0$ & $4,3 \pm 0,0$ \\
Iapar & $5,3 \pm 0,2$ & $4,2 \pm 0,2$ \\
Café comercial & $7,2 \pm 0,2$ & $4,7 \pm 0,1$ \\
\hline
\end{tabular}

Os valores de umidade apresentaram valores diferentes entre as espécies. A espécie arábica typica, catuaí vermelho e catuaí amarelo possui o mesmo teor de umidade, aproximadamente $2 \%\left(\mathrm{~m} \mathrm{~m}^{-1}\right)$, no entanto a espécie iapar possui o dobro do teor de umidade, $5 \% \mathrm{~m} \mathrm{~m}^{-1}$. Verificou-se que o teor de umidade do café cultivado ao sol comumente comercializado é muito superior, aproximadamente $7 \% \mathrm{~m} \mathrm{~m}^{-1}$. 
Estes resultados indicam que o café sombreado produzido na região do Maciço de Baturité possui menores teores de umidade do que o café comumente comercializado, podendo ter maior tempo de validade e menor probabilidade de crescimento de microrganismos, como também maior quantidade de café por quilo comercializado.

Os teores de cinzas de todas as amostras de café sombreado estão aproximadamente $4 \%$ $\mathrm{m} \mathrm{m}^{-1}$, no entanto o café comercial possui aproximadamente $5 \% \mathrm{~m} \mathrm{~m}^{-1}$. Esse resultado sugere que o café sombreado produzido na região do Maciço de Baturité tenha mais conteúdo orgânico que os cafés comerciais, como também menor resíduo mineral.

\section{Conclusões}

As diferentes espécies de arábica produzidas na região do Maciço de Baturité possuem teores de umidade e cinzas diferentes dos teores do café cultivado em pleno sol que são comumente comercializados. O café sombreado do Maciço de Baturité possui menor teor de umidade e de cinzas sugerindo que a melhor qualidade do café produzido na região, com menor probabilidade de crescimento de microorganismos, maior quantidade de matéria por quilo de café e maior quantidade de matéria orgânica.

\section{Referências}

ALMEIDA, L. A.; ALMEIDA, F. M.M; MOURA, R. M. Influência do teor de umidade do café Arábica na rentabilidade do produto rural de Iúna-Es. VIII Simpósio de Excelência em Gestão Tecnologia.

Disponível:

https://www.aedb.br/seget/arquivos/artigos11/34414374.pdf. Acessado: 10/10/2018

CAMPANHA, M. M.; SANTOS, R. H. S.; FREITAS, G. B.; MATINEZ, E. P.; JARAMILLO-BOTERO, C.; GARCIA, S. L. Análise comparativa das características da serrapilheira do solo em cafezais (Coffea arabica L.) cultivados em sistema agroflorestal e monocultura, na Zona da Mata MG. Revista Árvore, Viçosa, 31 (5), 805 - 812, 2007.

FERNANDES, A; VICENTE DA SILVA, E.; PEREIRA, R. C. M. Fitogeografia do maciço de Baturité: uma visão sistêmica e ecológica. In: BASTOS, F. H. (org) Serra de Baturité: uma visão integrada das questões ambientais. Expressão gráfica e editora. Fortaleza, 2011.

INSTITUTO ADOLFO LUTZ. Métodos físico-químicos para análise de alimentos. Edição IV, $1^{\mathrm{a}}$ edição digital, São Paulo, 2008.

MANCUSO, M.A.C; SORATTO, R.P; PERDONÁ.M.J; Produção de café sombreado. Colloquium Agrariae, 9, 31 - 44, 2013.

SILVA, F.E.S. Conservação da biodiversidade da serra de Baturité na perspectiva das unidades de conservação. Tese de doutorado-Universidade Estadual do Ceará-UECE, p. 22, 2015. 